\title{
Using the iSDG Model as a Policy-Making Guiding Tool to Achieve SDG 4 in Developing Countries: A Case Study on Pakistan ${ }^{1}$
}

\author{
Faheem Khushik, Arnaud Diemer* \\ University of Clermont-Ferrand, Cerdi, Erasme, France \\ Email: *diemera@aol.com
}

How to cite this paper: Khushik, F., \& Diemer, A. (2021). Using the iSDG Model as a Policy-Making Guiding Tool to Achieve SDG 4 in Developing Countries: A Case Study on Pakistan Modern Economy, 12, 227-246.

https://doi.org/10.4236/me.2021.121012

Received: December 11, 2020

Accepted: January 26, 2021

Published: January 29, 2021

Copyright ( 2021 by author(s) and Scientific Research Publishing Inc. This work is licensed under the Creative Commons Attribution International License (CC BY 4.0).

http://creativecommons.org/licenses/by/4.0/

\begin{abstract}
Over the decades, educational systems around the globe evolved from simple to complex, with increase in its scope, spread, access and dynamic nature. This complex phenomenon needs simplified methods and models to explain/understand the systemic nature of cause and effect. This article pertains to exploring the dynamic educational context of Pakistan with focus on operationalizing SDG 4 and preparing children for a challenging future. System Thinking and System Analysis are used to map the main driving forces of the education system in Pakistan. Tools such as CLDs (Causal Loop Diagrams) illustrate the qualitative structure of the model. Variables such as educational access (number of enrolment at national level in primary to secondary level of education), inclusiveness budget (investment in education sector), GDP (ratio of GDP utilized on education), and equity (rate of gender per class), are analysed through loops to achieve SDG 4 targets. Both historically and currently, achieving Pakistan's educational objectives has been challenging. It requires a holistic approach for achieving objectives for example access to primary education.
\end{abstract}

\section{Keywords}

Sustainable Development Goals, Causal Loops Diagram, Education, iSDG, System Thinking, System Analysis

\section{Introduction}

The educational context of Pakistan is frequently discussed in reports, projects, programs and research articles (Hunter, 2020; Durrani \& Halai, 2018; Ha-

${ }^{1}$ We would like to thank Derek Chan, Matteo Pedercini (Millennium Institute-ERASME) and Claudiu Eduard Nedelciu (UCA, CERDI, ERASME) for their comments. 
meed-ur-Rehman \& Sadruddin Sewani, 2014; Tamim, 2014). The education system in Pakistan is complex and dynamic in nature because of continuous changes, inconsistent policies, multi-scales (urban and rural), gender discrimination, economic inequality or high level of out-of-school rates (Roohi, 2007). These are some of the main obstacles children are facing in society. Preparing children for future challenges is a prerequisite for achieving a sustainable society. Comprehensively addressing these challenges requires a systemic approach to explore dynamics in education and their linkages with challenges associated with promoting peace, sustainability, and global citizenship (Mochizuki, 2019). The educational system faces many internal and external challenges. Policy, administration, political interference and political influence need to be addressed in an effective way to improve its inputs and outputs/outcomes. The primary purpose of education for Pakistan is to achieve economic objectives (Afzal et al., 2010; Babar et al., 2008) as well as social development (Rasool Memon, 2007). To do so, Pakistan needs a transformation of its education strategies, so that it cannot only achieve the country's priorities but also achieve the global climate objectives that the state has committed to during the Paris summit of 2015 (Arnold \& Wade, 2015; Kakakhel, 2015; Sayed \& Ahmed, 2015; McGrath \& Powell, 2016). Following the Paris Agreement, a central sustainable development unit was established to research, report, collect data and coordinate among government departments and regions to synchronize sustainable development efforts at national level. National level meetings, reports and data collection tools were modified and regional development projects, plans and programs were revised to achieve targets within a given time frame (Khushik \& Diemer, 2018). One of them-Sustainable Development Goal 4 "Ensure inclusive and equitable quality education and promote lifelong learning opportunities for alp'-is a global agenda for educational objectives set for the year 2030 (Cho et al., 2017). Its targets and indicators are widely spread all over the globe to achieve the global objective of education for maximum children (Unterhalter, 2019).

However, historical results show a trend of inefficiency when it comes to achieving educational targets in Pakistan (Khushik \& Diemer, 2018). The country remained far behind in achieving the targets of the Millennium Development Goals (MDGs), education for all and all its internally-set targets in each educational policy (Attaullah \& Malik, 2015; Rizvi, Bhatti, Das \& Bhutta, 2015). This is still the case with the Sustainable Development Goals (SDGs), where insufficient progress has been made for reaching SDG 4 targets (Ghaus et al., 2015; Seeme, 2017). In its SDG 4 gap analysis report, the United Nations Education, Scientific and Cultural Organisation (UNESCO) mentions that "Pakistan faces severe challenges with regards to achieving SDG 4, 22.6 million children aged 5 - 16 years are out of schoop' (UNESCO, 2020). These challenges concern poverty, accessibility, quality teaching, quality of curriculum, budget constraints, corruption, political interference, inequality, gender discrimination, geographic spread or different cultures, centralization and so on (Roohi, 2007).

One explanation for this situation is that educational challenges or targets are 
tightly coupled with economic growth (Diemer, Khushik, \& Ndiaye, 2020). The growth of the Gross Domestic Product (GDP) is a prerequisite to educate more people and set the country on the high-quality education pathway. Econometrics models (Jalil \& Idrees, 2013) and Computable General Equilibrium Models (Siddiqui, 2006) used to study this correlation show the lack of efficiency of capturing the structure of the educational system, together with its different feedback effects. The official UNESCO SDG 4 gap report highlights some measures to enhance pace of achieving targets by improving data collection quality with consistency, regular monitoring with concrete indicators and evaluation of progress (Khushik \& Diemer, 2020a). At the state level within Pakistan, a clear mapping has been done to roll out a policy or program for SDG 4 achievement (Khan \& Ali, 2019). Within the country, different regions/provinces devolve the education department from centre to provinces/regions therefore every region is now independent in policy, planning, implementation and outcome after the 18th constitutional amendment in 2010 (Sohoo et al., 2019). On one hand, decentralization decreases tiers to manage but on the other it poses challenges of capacity (Davood, 2009). Country capacity and resources are also raising questions for not being able to achieve objectives. Primary and secondary education is under provincial domain except higher education in universities, which is managed and administered by the Higher Education Commission (Parveen et al., 2011). Regions/provinces have their own challenges apart from above-mentioned issues such as cultural barriers which hinders girls to go to school (Arai \& Tabata, 2006). The Planning commission of Pakistan took the lead in conceptualization of the national framework (Khemka \& Kumar, 2020). All education sector short, medium and long term projects have been modified with special focus on access, quality and governance. Due to a significant portion of private schools' enrolment it is more complicated to mobilize private schools for incorporating national objectives and follow national policy (Sohoo et al., 2019). But "to achieve success on SDGs agenda a strong partnership between public and private sector and civil society is needed".

The National SDGs framework proposed some targets regarding SDG 4. Target 4.1 stipulates that $100 \%$ (girls + Boys) will finish basic primary education by 2030 as compared to the current $57 \%$ literacy rate. Target 4.5 stipulates an increase of the current GPI from 0.87 now to 1 in 2030. With these nationalized targets, Pakistan is hoping to achieve some of SDG 4 targets on time (Umar \& Asghar, 2018). Nevertheless, it will be extremely challenging for the state to achieve objectives within a given time frame till 2030 (Khushik \& Diemer, 2020b). With a fast-growing population, Pakistan is already the sixth most populous country in the world with 221 million people and this number is expected to reach 338 million by 2050 (UN Population Statistics 2020). At present, 63\% of Pakistanis are under the age of 30 (UN Population Statistics, 2020 https://www.un.org/en/sections/issues-depth/population/). Education will ${ }^{2}$ SDGs Pakistan.

https://www.sdgpakistan.pk/uploads/pub/National_SDGs_Framework_-_NEC_20182.pdf. 
thus play a key role in the modernization of the country and the achievement of its SDG agenda through its positive (direct and indirect) impacts on economic and social development, from primary level (Iqbal \& Zahid, 1998) and secondary level (Abbas \& Foreman-Peck, 2008). Developing robust education strategies requires tools that can capture, analyse and quantify the interrelation between education and other sectors, particularly in the perspective of achieving the Sustainable Development Goals (SDGs). This article reviews such a tool, namely system dynamics (SD) modelling, by examining the development of two widely-used development models: the T21 and the iSDG. A case study analysis on Pakistan is then carried out using literature review and Causal Loop Diagrams (CLD), followed by a discussion on the main dynamics that are central to the achievement of SDG 4 for the country.

\section{Methodology and Research Design}

The overall theoretical framework of this article is Systems thinking, which encompasses "a large and fairly amorphous body of methods, tools and principles, all oriented to looking at the interrelatedness of forces, and seeing them as part of a common process" (Senge, 1990). A system is a perceived whole whose elements work together because they continually affect each other over time and operate toward common purpose. In Systems Thinking, the structure of the system plays an important role. The structure is the pattern of interrelationships among key components of the system. That includes the hierarchy of the flows, attitudes and perceptions, the ways the decisions are made. For Senge (1990), systems thinking introduce four levels operating simultaneously: events, patterns of behavior (over time), systemic structure and mental models. Systems Thinking usually describes how the world works (mapping the system) by using Causal Loops Diagram (CLD). CLDs define the qualitative structure of the model. It's also possible to use Systems Thinking to imagine how the world could be (scenario) (Figure 1).

One application form of System Thinking (Goodman, 1997; Richmond, 2000; Richmond, 1997) has become particularly valuable as a language for describing how to achieve fruitful change in organizations. This application form is called

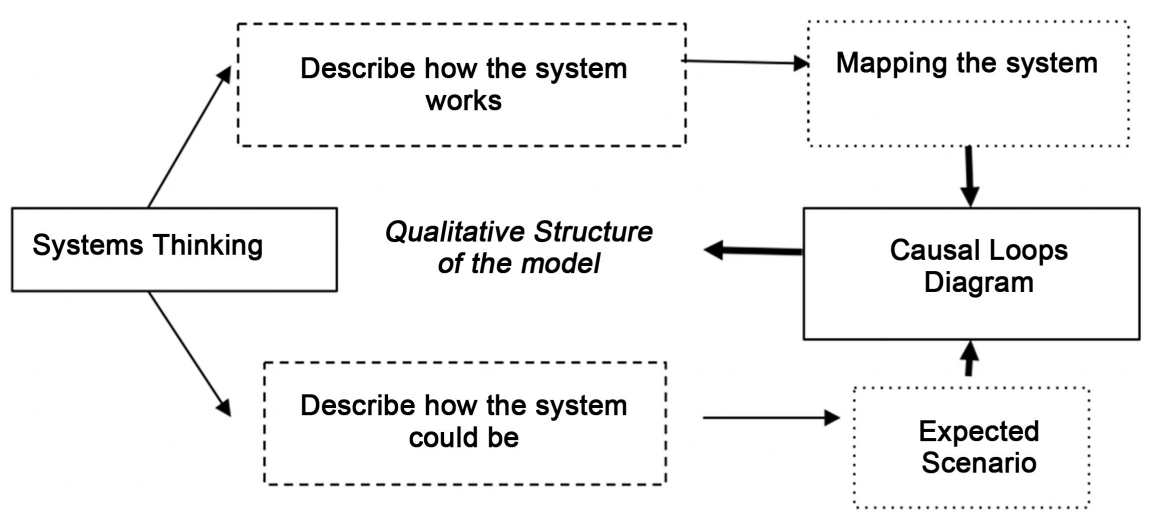

Figure 1. Systems thinking and qualitative design of a model. Source: Diemer (2020, 2004). 
System Dynamics (Forrester, 1961, 1969; Pruyt, 2013). System dynamics-via causal loop diagrams (CLD) and stock-flows diagrams (SFD) - is the study of dynamic feedback systems using computer simulation (using VENSIM, STELLA or POWERSIM software). It applies to dynamic problems occurring in complex social, management, economic or ecological systems-literally any dynamic system is characterized by interdependence, mutual interaction, information feedback and circular causality.

In order to assess the usefulness of SD modelling for policy design in achieving SDG 4, this paper is based on a case study review on the use of SD modelling in education, with a focus on two major SD models, the T21 and the iSDG, developed by the Millennium Institute (Qu, Barney, Symalla, \& Martin, 1999). These models were chosen for two main reasons. First, because they have been applied in a number of developing countries around the world and so they constitute an already tested policy-guiding tool. Second, because the iSDG is a revised version of the T21 model, which allows an examination into the main evolutionary changes that have occurred so far, while enabling an analysis of how the model can improve into the future to better respond to policy challenges. Causal Loop Diagrams will be used in the discussion part of this paper, where the implications of SD modelling of the Pakistani education sector, particularly through the T21 and iSDG, are examined. These diagrams lead us to see causality as an "ongoing process", rather than a one-time event.

The language of Systems Thinking is "links" and "loops". From any element in a situation (variable), it's possible to trace arrows (links) that represent influence on another element. These links may reveal cycles that repeat themselves, time after time. Links never exist in isolation, they always comprise a circle of causality - a feedback loop in which every element is both cause and consequence. There are basically two representations of loops-reinforcing and balancing loops (Figure 6). Reinforcing loops (R) have a positive polarity (+), generating exponential growth and collapse, which continues at an ever-increasing rate. Balancing loops (B) generate resistance's force (which may limit the growth). Balancing loops have a negative polarity (-) and are found in situations which are self-correcting and self-regulating (Figure 2).

Balancing and reinforcing loops often introduce time delays. Delays may have important consequences in a system, frequently accurating the impact of other forces. Loops and delays are part of the Causal Loops Diagram (CLD). CLDs help visualize the structure and behavior of a system, and to analyze the system in a qualitative way. This point is important because it reminds us that a model is above all qualitative (it must be based on hypotheses that need to be tested, this is the structural model). In addition, CLDs enable us to identify leverage points of intervention in the system and approximate the effectiveness of a certain policy intervention on the overall system (Meadows, 1999, Table 1).

System Dynamics uses models to explore the link between system structure and time evolutionary behavior. The aim is twofold: 1) explain behavior by 


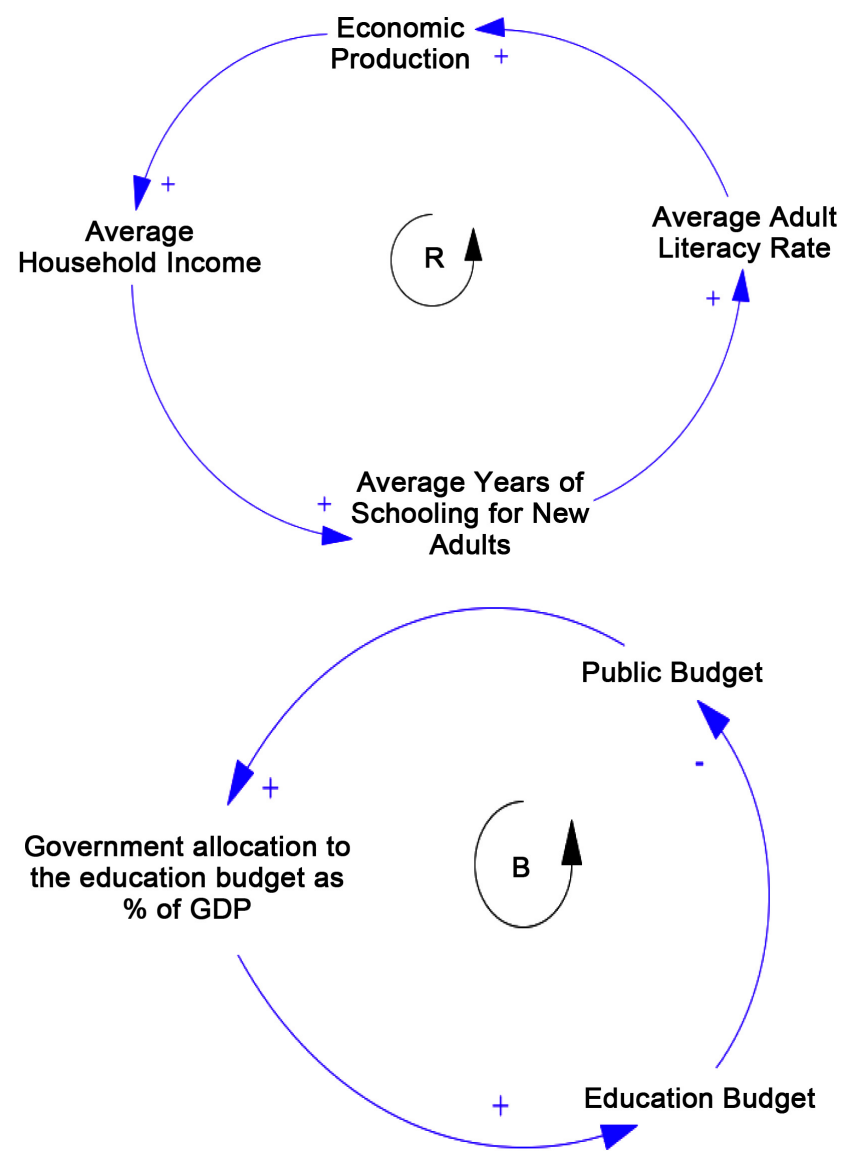

Figure 2. An example of a Reinforcing (R) loop and a balancing (B) loop (B). Source: The authors.

Table 1. Leverage points of Donella Meadows. Places to intervene in a system (in increasing order of effectiveness).

12) Constants, parameters, numbers (such as subsidies, taxes, standards)

11) The sizes of buffers and other stabilizing stocks, relative to their flows.

10) The structure of material stocks and flows (such as transport networks, population age structures)

9) The lengths of delays, relative to the rate of system change

8) The strength of negative feedback loops, relative to the impacts they are trying to correct against

7) The gain around driving positive feedback loops
6) The structure of information flows (who does and does not have access to what kinds of information)

5) The rules of the system (such as incentives, punishments, constraints)

4) The power to add, change, evolve, or self-organize system structure

3) The goals of the system

2) The mindset or paradigm out of which the system-its goals, structure, rules, delays, parameters-arises

1) The power to transcend paradigms

Source: Meadows (1999). 
providing a causal theory; 2) use that theory as the basis for interventions into the system structure which then change the resulting behaviour mode. The concept of feedback is at the heart of the System Dynamics approach. Information feedback loop diagrams and circular causality diagrams are tools for conceptualizing the structure of a complex system and for communicating information based on models (also considering the time delays of feedback loops).

The System Dynamics methodology involves the dominance and non-linearity of loops, the concept of endogenous change, a system structure (system boundaries, feedback loops, levels and rates, objective, observed state, deviation, desired action), stocks (levels) and flows (rates) as essential components of the system structure, and behavior because of the structure. The transition to system dynamics allows the integration of qualitative and quantitative approaches to the model, which via computer simulation, allows long-term simulations (10 - 25 50 - 100 years). This last point is crucial, as the model does not give forecasts but long-term trend evolutions. As such, it is a good decision-making tool (Figure 3).

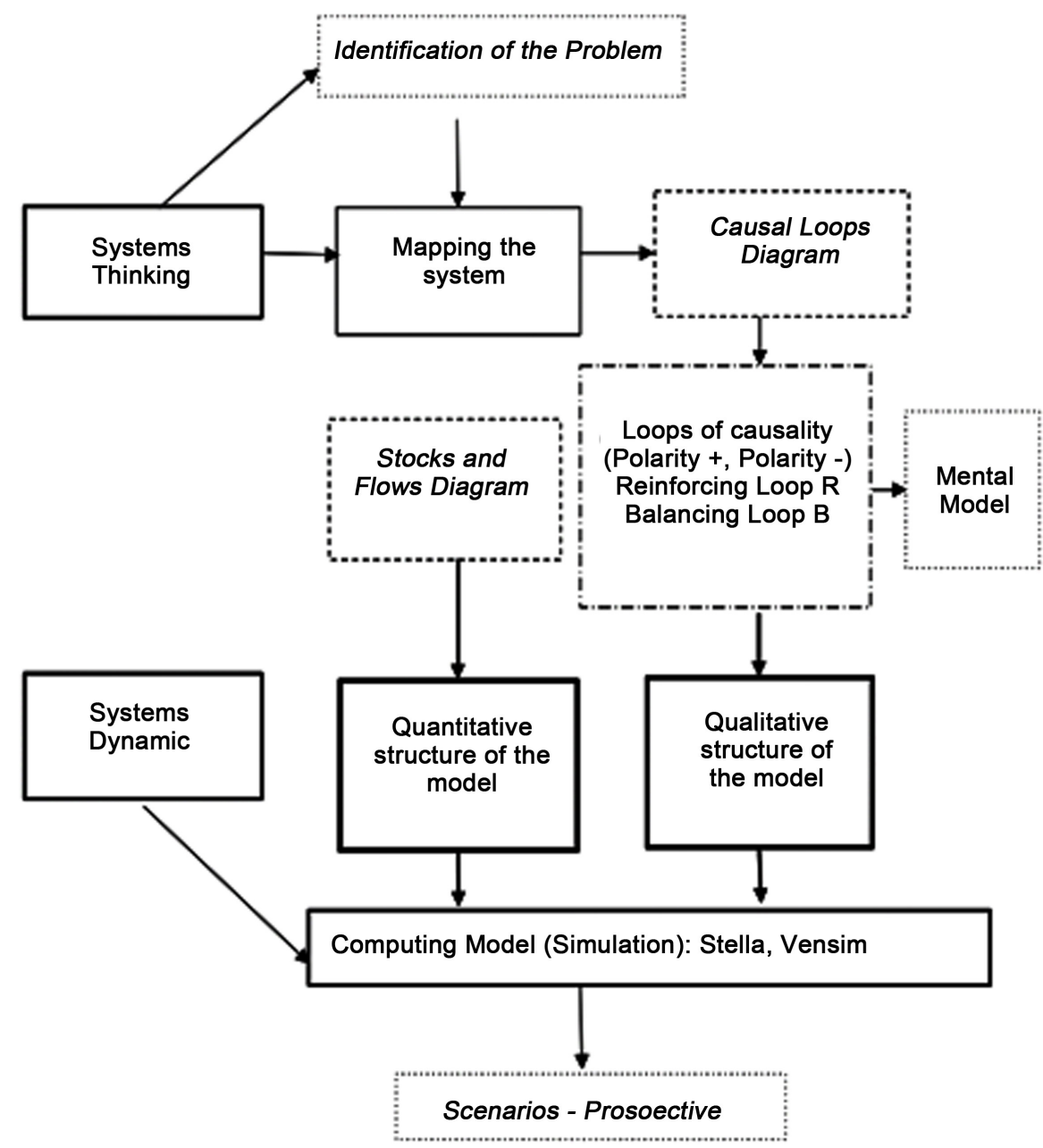

Figure 3. Systems thinking, systems dynamic, models and simulation. Source: Diemer (2020, 2004). 


\section{3. iSDG Model}

In 2015, the General Assembly of the United Nations adopted the 2030 Agenda for Sustainable Development, consisting of 17 Sustainable Development Goals (SDGs) and related targets (A/RES/70/1). The resolution highlights that "the interlinkages and integrated nature of the SDGs are of crucial importance" and that "the challenges and commitments identified... are interrelated and call for integrated solutions". In order to address the need for planning tools in this framework, the Millennium Institute developed the iSDG (Integrated Sustainable Development Goals) model for medium- and long-term national planning towards the SDG. The iSDG model is the latest in the line of System Dynamics-based T21 models developed by the Millennium Institute that have been adapted and applied to more than 30 countries around the world (Millennium Institute, 2007a, 2007b). System Dynamics deconstructs the relationships among many variables and is particularly relevant for studying complex socioeconomic environments (Sterman, 2000). The model could help with integrated decision-making for policy makers, provide insight into the interlinkages across SDGs and inform on budgeting and planning to improve Pakistan's educational objectives. In this section, we describe the evolution of how Education has been represented in the iSDG and T21 models prior to this.

\subsection{T21 Model Framework}

The iSDG model is the latest in a line of models called the T21 developed by the Millennium Institute. The original T21 models were based on a detailed review of the development modeling research, including from such sources as the World Bank, IMF, IPCC, the United States Department of Energy. This culminated in the publication of a book edited by Barney, Kreutzer and Garrentt (1991) that allowed the government and other decision-makers to plan for integrated decision-making. Over time, the T21 has evolved, incorporating additional structures depending on needs and verified by academics and practitioners in the field through group model building and practical applications of the model.

\subsection{MI’s T21 Model}

1) Integrates three domains (economy, social and environment). Within each domain are sectors that interact with each other and with sectors in the other domains (Figure 4). The Economy domain (red) contains major production sectors (agriculture, industry, services) which are characterized by Cobb-Douglas production functions with inputs of resources, labor, capital and technology. Demand is based on population and per capita income and distributed among sub-sectors using Engle's Curve. The Social domain (red) contains detailed population dynamics by sex and age cohort, health and education challenges and programs; basic infrastructure; employment; and poverty levels and income distribution. The Environment (green) tracks pollution created in the production 


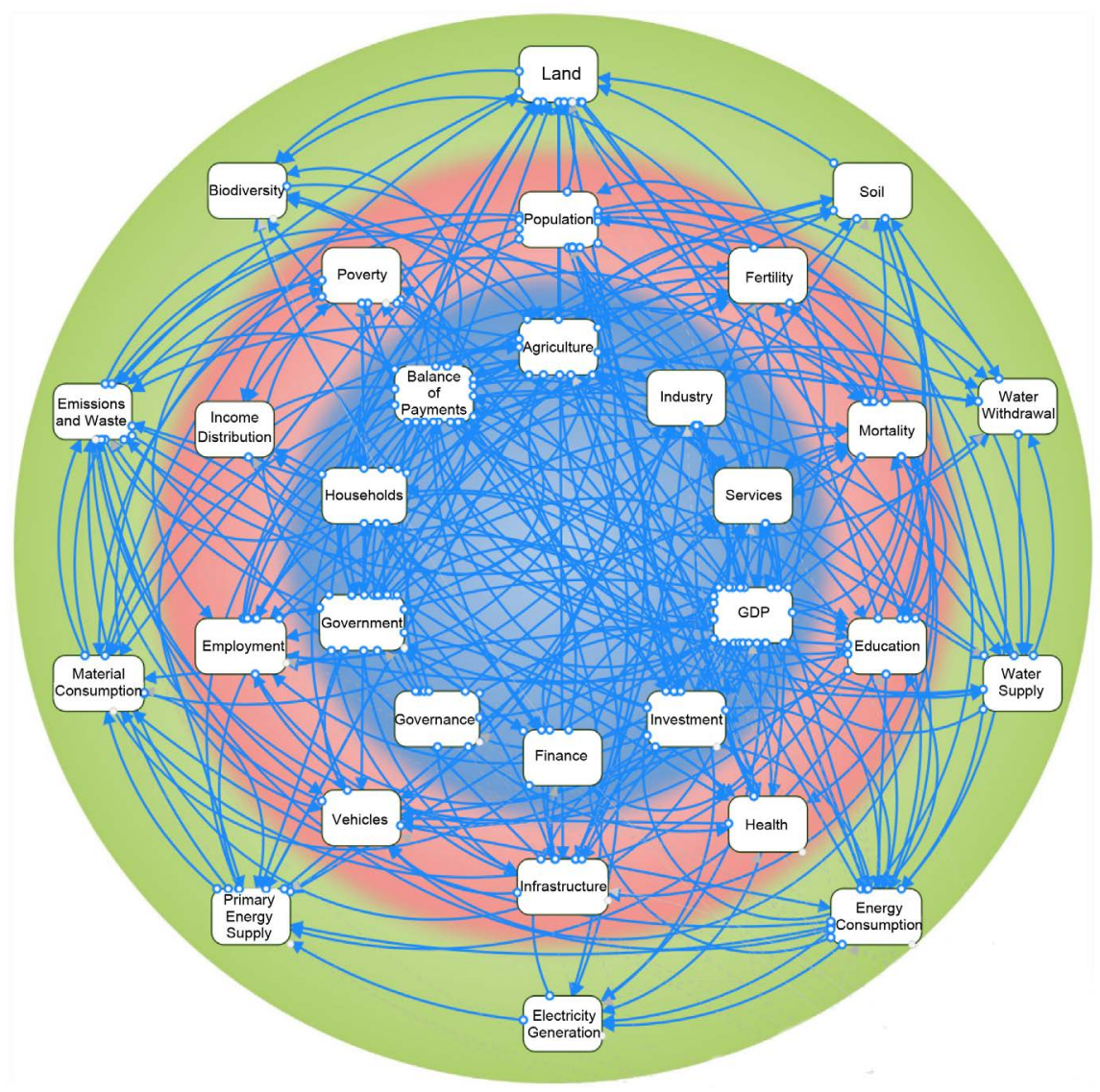

Figure 4. Framework of the T21 model. Source: Millennium Institute.

processes and its impacts on health. It also estimates the consumption of natural resources (renewable and non-renewable) and can estimate the impact of the depletion of these resources on production and other factors (Millennium Institute, 2017).

2) Represents the important elements of complexity that we find in the Systems Dynamics approach (feedback relationships, non-linearity, time delays).

3) Is transparent in its structure (assumptions, equations, data requirement), so as to serve as a participatory tool in consensus building and policy discussions.

4) Is flexible to be customized to specific countries by training users based on country specific conditions (Bangladesh for Health care, nutrition and education in 1994; Tunisia for water and revisited fertility in 1996; Cambodia for effects of war in 1997; China for relative prices, transportation and Chinese interface in 1999; Guyana for structural adjustment of sugar and bauxite industries in 2001; Mozambique for micro-credit, agricultural extension, new roads and Millennium Development Goals in 2003, Mali for Cotton production and gold extraction in 2005; Jamaica for Crime, natural disasters, sugar cane production in 2006).

5) Simulates the short and the long-term consequences of alternative policies.

6) Permits comparison to reference scenarios and supports advanced analyti- 
cal methods such as sensitivity analysis and optimization.

The Threshold 21 was a generic structure that represented development mechanisms that can be found in most developing and industrialized countries. It covered a broad range of issues that countries all over the world face: poverty, environmental degradation, health, economic growth, demographic expansion or education. The boundaries of the system were defined by the status of the different variables (endogenous, exogenous and excluded variables), the level of aggregation (national level), the geographic limits (the country and the rest of the world) and the time horizon (long term development issues).

T21 was a relatively large size model, composed of more than a thousand equations and included about 60 stocks variables and several thousand feedback loops. The complexity of the model is organized into modules, sectors and spheres.

In the T21, the Education sector belongs to the social sphere and is composed of two modules: primary education and secondary education. The primary education module represents the progression of children through primary school to becoming part of the literale population (Figure 5). The major output of the module was the adult literacy rate (male and female) which affected many other sectors including population and Production sectors. Major assumptions were: 1) Entrance and dropout rates depend on income and government expenditure per school age child; 2) primary school lasts for 6 years; 3) Graduates from primary school at grade one; 4) the children in school have the same life expectancy as the children who do not go to school; 5) migration of children in school is not

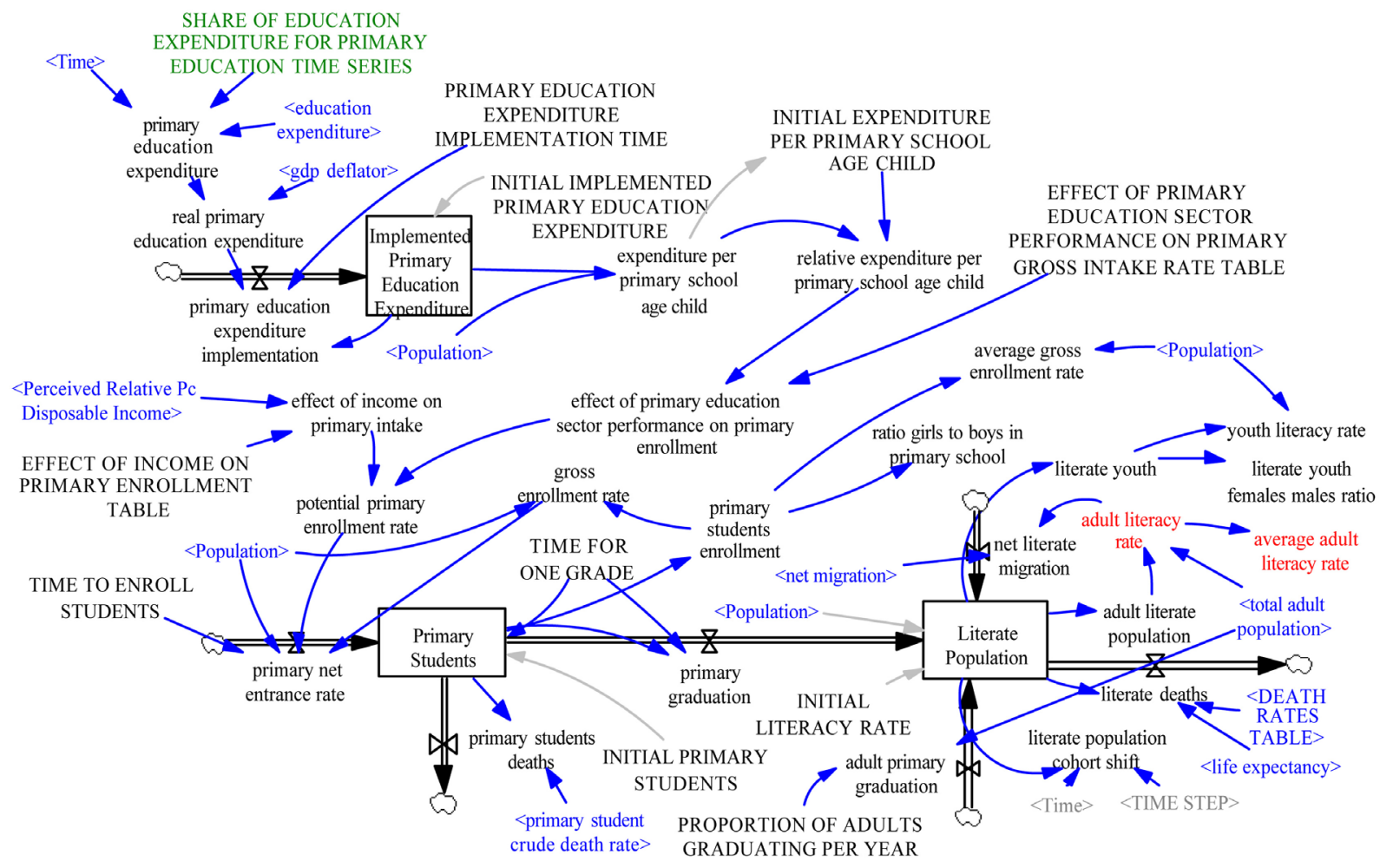

Figure 5. Primary education module. Source: Millennium Institute (2007a: p. 29). 
Considered; 6) the literate population has the same life expectancy and migration behavior as the rest of the population. The primary Education module is presented as a Stock-Flow Diagram (SFD). Stocks are the implemented primary education expenditure, the primary students and the literate population.

The secondary education module is built on the same basic structure of the Primary Education module. It represents the process of students going through secondary school and eventually becoming a part of the population with a secondary degree (Figure 6). Students are disaggregated by both year and gender so that gender related education issues could be addressed. The major inputs of the module are total secondary graduates and secondary students enrolment (both sexes) which affect many other sectors, including the labor sector.

The T21 Model has evolved over two decades as applications to individual countries. It has been continuously improved and redesigned to integrate effective strategies to achieve the SDGs. This model is a tool to support policy makers in establishing policy coherence and building an integrated view on development strategies.

\subsection{General Characteristics of iSDG Model and Education Sector}

The iSDG model integrates in a single framework the economic, social, and environmental aspects of development, providing a comprehensive and long-term perspective on a country's possible futures. The model simulates the fundamental

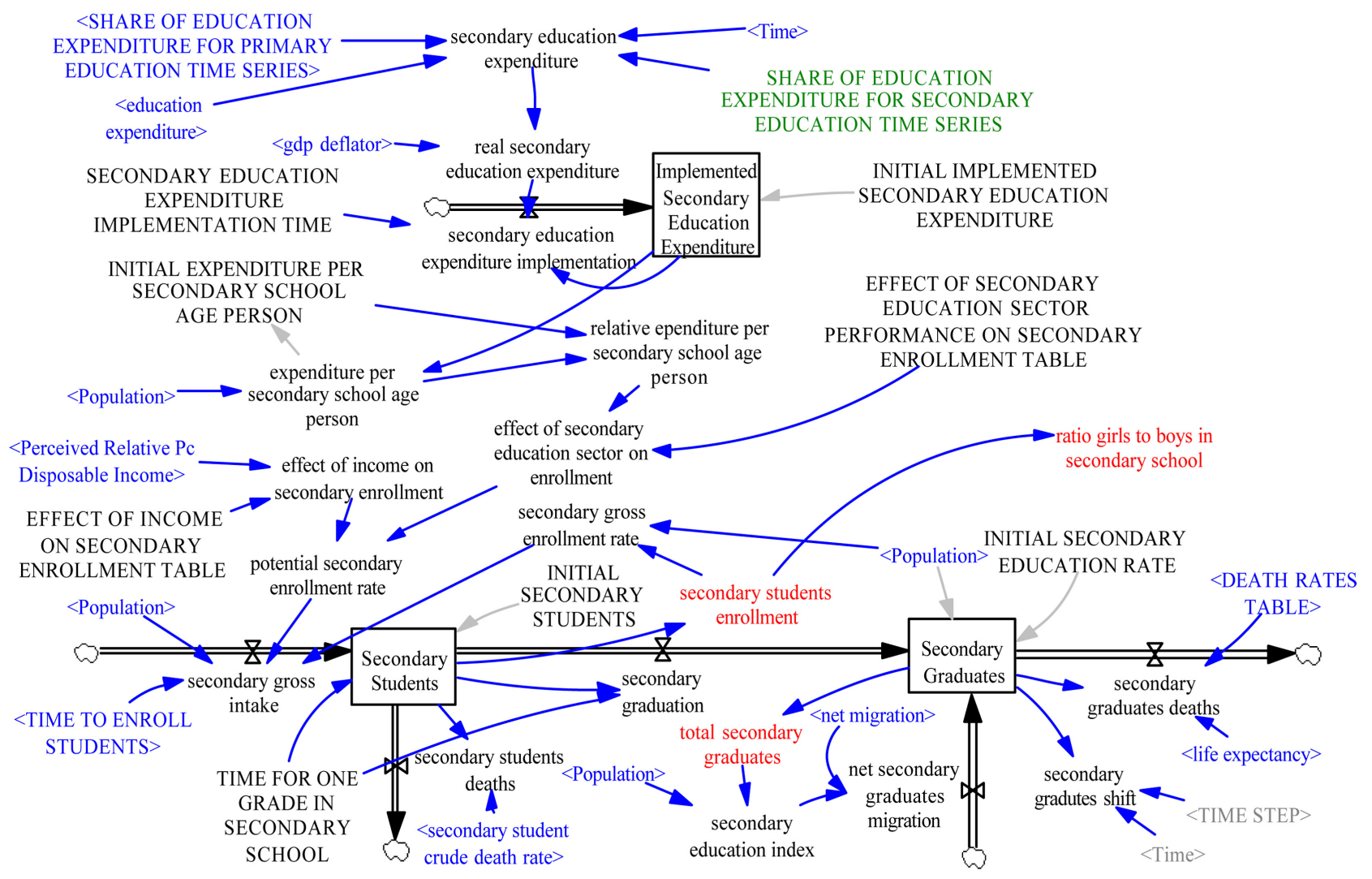

Figure 6. Secondary education module. Source: Millennium Institute (2007a, 2007b: p. 33). 
trends for SDGs until 2030 under a business-as-usual (BAU) scenario, and supports the analysis of alternative strategic scenarios. Cross-sector impacts of individual policies can be traced and assessed, and synergies emerging from the interaction of multiple policies can be identified, quantified and leveraged. iSDG models undergo a policy process of five stages or steps: $1^{\circ}$ Agenda setting/identification of issues; $2^{\circ}$ Policy design/formulation/assessment; $3^{\circ}$ Policy adoption; $4^{\circ}$ Policy implementation; $5^{\circ}$ Policy assessment/monitoring/evaluation. However, its focus is more on stage 2 in supporting policy design of a complex sector of multiple stakeholders. It is generally believed as a participatory model in a sense that it integrates all three perspectives of SDGs: economic, social and environmental.

Model uses three customized indicators in a sense to analyse policy on measuring a specific target of a goal for example in education goal 4 below targets have been used as indicators (Table 2).

The core area of education iSDG is simulating the policy for the public education sector of Pakistan. Broad scope and nature of the model covers a range of issues and problems. Another characteristic of the iSDG model is very much relevant is its data aggregation level. "iSDG is conceived as a national model and, from a geographic perspective, data are aggregated at the national level"3. Using the approach of iSDG model is also because it is centred on the internal long term issues of a country therefore it is very much suitable in the context of Pakistan's progress on sustainable issues. It also determines how an output of a problem relates to the world for example $\mathrm{CO}_{2}$ emission. The time horizon is 1990 to 2030 in order to capture both historical perspectives and attainment towards the 2030 agenda.

In its structure, the iSDG model is complex and large in size. It consists of thousands of sticks, several feedback loops and sectors. In order to simplify the model, it is divided into smaller logical units labelled as sectors. Each sector has its internal mechanism that can be understood in isolation from the rest of the model. The 30 sectors composing iSDG include: 10 social sectors (Education, health population etc.), 10 economic sectors (Agriculture, industry services etc.),

Table 2. SDG4 indicators.

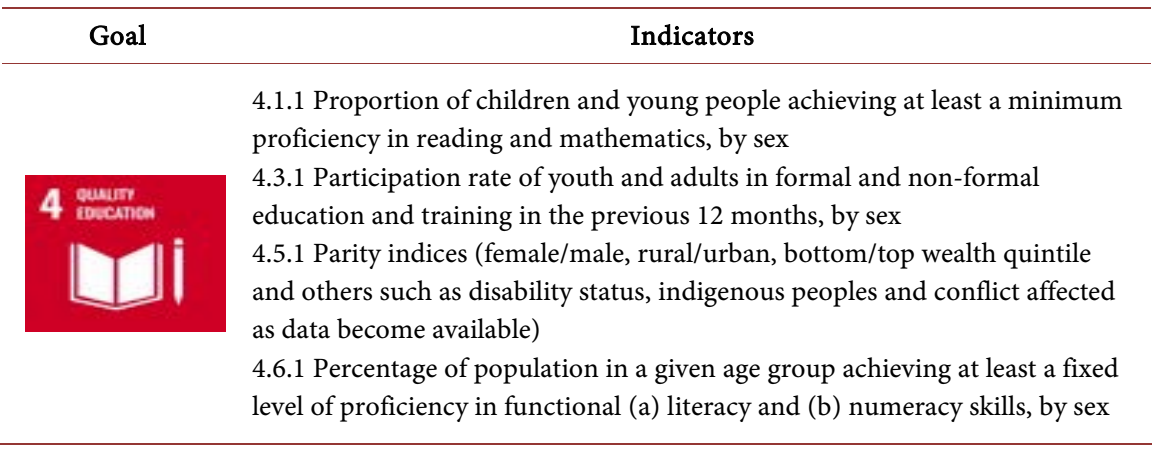

Source: United Nations (2015).

3“iSDG-Millennium Institute.” https://www.millennium-institute.org/isdg. Accessed 13 Aug. 2020. 
and 10 environmental sectors (Land, soil, water etc.). The sectors interact with one another dynamically through a complex network of feedback loops. The selection of the sectors is based on the desired ability of the model to properly track the SDGs and simulate relevant policies.

\subsection{Endogenous, Exogenous and Excluded Variables}

"iSDG's fundamental approach is to endogenously represent variables that are considered an essential part of the development mechanisms under analysis. For example, the Gross Domestic Product (GDP) and its main determinants, population and its main determinants, and the demand and supply of natural resources and their main determinants are endogenously calculated ${ }^{4 \prime}$. Variables are determined by context and nature of endogeneity and exogeneity and then considered as strong or weak variables and factors impact on each other. In this context if some variables are out of scope of analysis, that has no quantifiable impact on issues analysed that are not explicitly represented. It does not mean that their effect is not considered but their effect is included in the parameters of the model.

\subsection{Education Module in iSDG}

The education module in the iSDG tracks the average enrolment rate by sex (female or male) and by education level (pre-primary, primary, secondary and tertiary). The enrolment rates are constrained by public school capacity and increases if more students are in the private education system. School capacity is determined by education expenditure (UNESCO, 1984), which is ultimately affected by overall government expenditure. Other factors that impact the enrolment rate include access to electricity (Leipziger et al., 2003), governance (World Bank, 2012; Al-Samarrai, 2013; Rajkumar \& Vinaya Swaroop, 2002), road infrastructure (Calderón \& Servén, 2004), health (Behrman, 1996), and income (Pritchett \& Filmer, 1998). Additionally, cultural and economic factors may introduce a gender bias in certain contexts (Shahidul \& Zehadul Karim, 2015). Thus, the enrolment rate may be skewed towards one sex or another and dropout rates may increase. The model calculates the likelihood to drop out given these factors and capacity restrictions. If a child has not completed primary schooling, they cannot proceed to secondary schooling.

The model considers the current enrolment levels to determine the school achievement of young adults. The model is calibrated to education data from Barro \& Lee (2013), which includes seven levels of education, namely: no education (E0), some primary education (E1), primary education completed (E2), some secondary education (E3), secondary education completed (E4), some tertiary (E5), and tertiary education completed (E6). The distribution of education will feed into a population aging chain that captures the education levels of the

\footnotetext{
4"iSDG-Integrated Sustainable Development Goals Model...”
}

https://www.millennium-institute.org/isdg. 
entire population, from which the overall population average years of schooling and literacy rates are calculated (Figure 7).

In addition to mapping the key factors that determine the level of education, this structure takes into account the significant time that it takes to increase the level of education in the population. Not only does it take a significant amount of time to achieve literacy in school-aged children, adults already in the workforce take significant time to age out of the workforce.

\section{Discussion}

The following causal loop diagram (Figure 8) demonstrates interrelationship between different socio-economic sectors that one sector positively affects another loop except the two highlighted in red. The detailed discussion about the diagram below is given however in general it indirectly demonstrates educational challenges. This model depicts the country context regarding education. There are some internal and external loops. Here internal means within the education sector such as availability of electricity and external for example government expenditure. Therefore, both types of factors are analysed and necessary to study.

This causal loops diagram shows the main socioeconomic drivers of education (access to electricity, transport infrastructure, average life expectancy, education infrastructure and average household income). If the school-aged population were lower, all else equal, education success would be higher, as per-capita

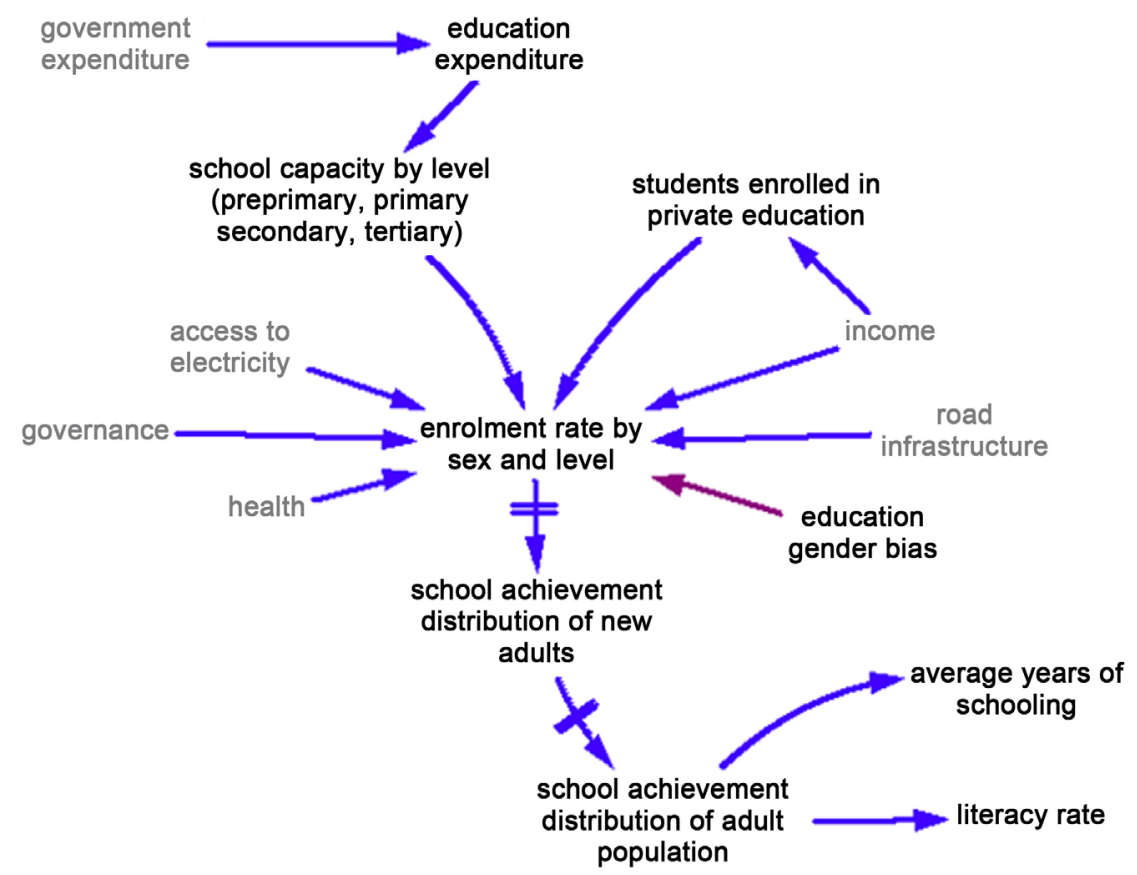

Figure 7. Drivers of school achievement distribution of adult population. Source: The Authors. Simplified causal structure of the Education module with links to other modules (variables in grey), positively correlated relationships (blue), and significant delays marked (two dashes through the arrow). 


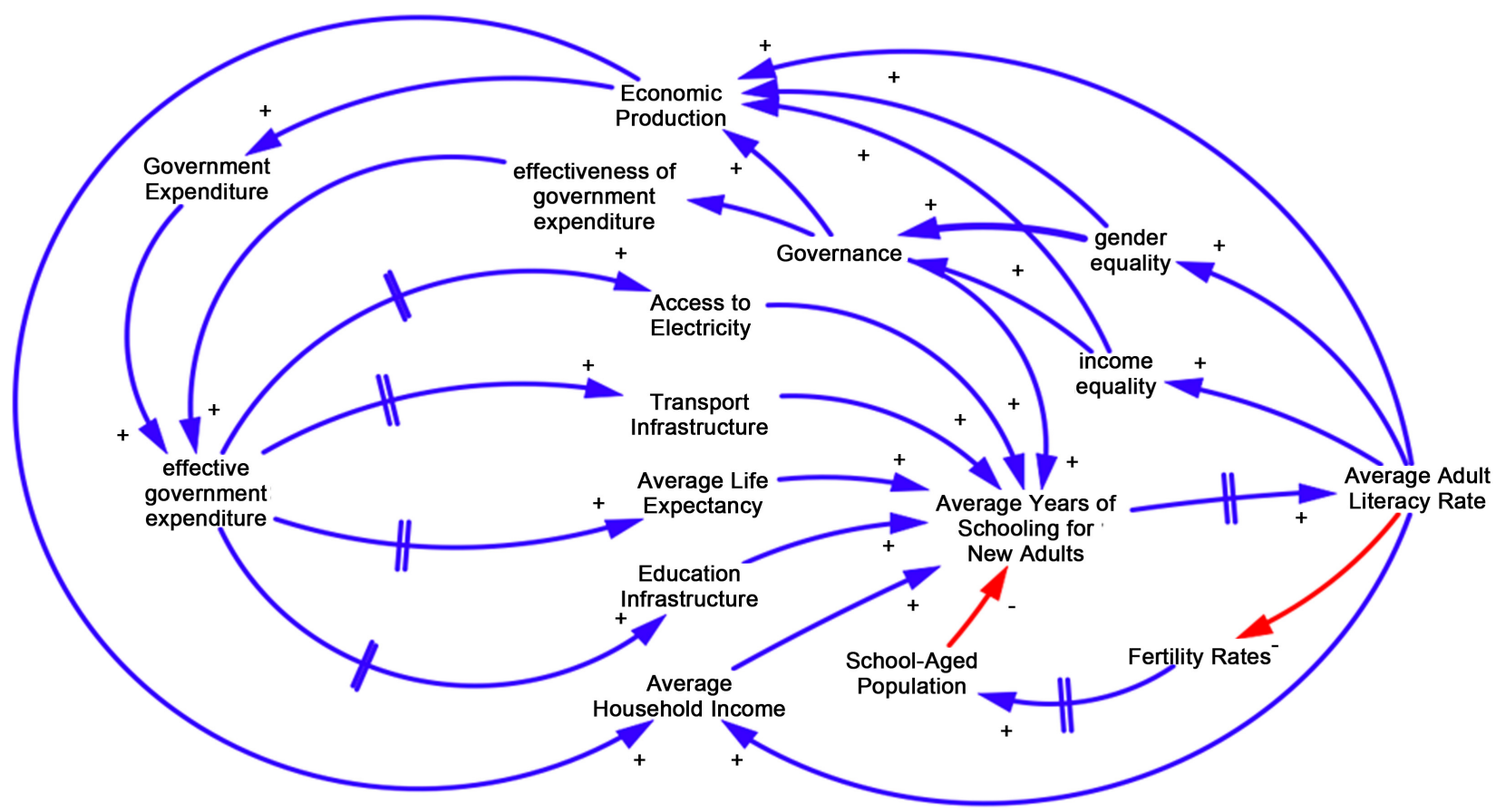

Figure 8. Drivers of average adult literacy rate. Source: The authors.

expenditure is greater. In this diagram, blue arrows represent a positive relationship between the two variables (i.e. if the first variable increases, the second increases as well, or if the first decreases, the second will also decrease). Red arrows represent a negative relationship between the two variables (i.e. if the first variable increases, the second will decrease, or if the first decreases, the second increases). Arrows that contain slashes show potential significant sources of delay. For example, although recent graduates may be better educated, it may take years or decades before the overall literacy rate of the population experiences significant changes, as the improved literacy is typically only in the younger population and must replace the population over time.

The diagram shows multiple opportunities for reinforcing improvements in education. As better education is a driver of economic productivity (human capital), this can in turn increase tax revenues and government spending. This government spending can then be used towards improving electricity, transport, health and education infrastructure, which will all in turn increase the predicted average years of schooling for new adults. Additionally, improved literacy rates across the population will improve gender and income equality as larger proportions of the population are educated and can access better economic opportunity. Along with improved economic production, governance tends to improve gender and income equality. With improved governance comes better economic production (stemming from improved processes for businesses, lower corruption), and higher effectiveness of government expenditure, as society has higher trust in government and it is more effective. This further reinforces the improvements in economic production. Additionally, higher literacy rates typically 
Table 3. Indicators of the drivers.

\begin{tabular}{cc}
\hline Drivers & 2019 \\
\hline Government Expenditures (PKR in millions) & $6,419,111$ \\
Education Affairs and Services (PKR in millions) & 97,155 \\
Government Expenditure on Education (\% GDP) & 2.8 \\
Expected years in schooling & 8.5 \\
Expected years in schooling (male) & 9.3 \\
Expected years in Schooling (female) & 7.8 \\
Literacy rate, adult (\% ages 15 and older) & $57 \%$ \\
Fertility rate (births/woman) & 3.488 \\
Income inequality (Gini Coefficient) & 33.5 \\
School Aged Population (5 - 16) (in millions) & 51.8 \\
Out-of School children (in millions) & 22.8 \\
Gender Inequality Index & 0.547 \\
Average household Income (PKR) & $498,540,000$ \\
Life expectancy at birth (years) & 67.1 \\
Total Road Paved (kms) & 55 \\
Road Density (km/km ${ }^{2}$ ) & $156,000(60 \%)$ \\
Access to Electricity-All population-Urban-Rural (\%) & 0.32 \\
\hline
\end{tabular}

Source: Finance Government of Pakistan, UNDP, World Bank, ADB, UNICEF (2019).

lead to lower fertility rates. With lower demand for schooling, the strain on school infrastructures will lessen, further improving schooling outcomes (Table 3).

\section{Conclusion}

System dynamics models have become reliable tools in developing and accessing robust education policies, particularly through their capacity to capture and quantify complexity and cross-sectoral dynamics. In Pakistan, addressing the multi-faceted education sector has been a challenging task for policy-makers and the country has been underperforming in its progress to achieve SDG 4. By using SD models with a track-record of real-life application, such as the T21 and iSDG models reviewed in this paper, the country has the opportunity to advance a comprehensive development agenda and simultaneously evaluate and improve the efficiency of its implementation. Future research on the use of SD models for education in Pakistan that would address data inconsistencies, locally tailored methods for participatory approaches in the modelling process and conceptual frameworks on improved model structures (e.g. to the already existing education

${ }^{5}$ Gender inequality Index (GII): A composite measure reflecting inequality in achievement between women and men in three dimensions: reproductive health, empowerment and the labour market. ${ }^{6}$ Road density is $0.32 \mathrm{~km} / \mathrm{km}^{2}$ which is low and compares unfavourably with other South Asian countries (Bangladesh-1.7 km/km²; Sri Lanka- $1.5 \mathrm{~km} / \mathrm{km}^{2}$ and India, $1.0 \mathrm{~km} / \mathrm{km}^{2}$ ). 
sectors in the iSDG) can contribute to the development of a valuable policy-guiding tool. Such efforts would not only enable Pakistan to move towards achieving its SDG 4 targets, but it would also allow policy synergies to help the country in implementing its overall SDG agenda.

\section{Acknowledgements}

This project has received funding from ERASMUS + Programme of the European Union (Jean Monnet Excellence Center on Sustainability, ERASME).

\section{Conflicts of Interest}

The authors declare no conflicts of interest regarding the publication of this paper.

\section{References}

Abbas, Q., \& Foreman-Peck, J. (2008). Human Capital and Economic Growth: Pakistan, 1960-2003. Lahore Journal of Economics, 13, 1-27. https://doi.org/10.35536/lje.2008.v13.i1.a1

Afzal, M., Shaid Farooq, M., Ahmad, K., Begum, I., \& Quddus, M. A. (2010). Relationship between School Education and Economic Growth in Pakistan. Pakistan Economic and Social Review, 48, 39-60.

Al-Samarrai, S. (2013). Local Governance and Education Performance: A Survey of the Quality of Local Education Governance in 50 Indonesian Districts. Human Development. Jakarta, Indonesia, Washington DC: World Bank.

Arai, K., \& Tabata, Y. (2006). Socio Cultural Factors Affecting Girls' Limited Access to School Education in North West Frontier Province of Pakistan. APERA Conference, 28-30 November 2006, Hong Kong, 1-9. http://edisdat.ied.edu.hk/pubarch/b15907314/full_paper/1394178079.pdf

Arnold, R. D., \& Wade, J. P. (2015). A Definition of Systems Thinking: A Systems Approach. Procedia Computer Science, 44, 669-678. https://doi.org/10.1016/j.procs.2015.03.050

Attaullah, M., \& Malik, S. Y. (2015). MDGs on Universalization of Primary Education: Analysis of Gaps Between Commitment and Implementation in Pakistan. Mediterranean Journal of Social Sciences, 6, 224-231. https://doi.org/10.5901/mjss.2015.v6n6s1p224

Babar, A., Tasneem, K., \& Shumaila, A. (2008). Impact of Higher Education on Economic Growth of Pakistan (22 p). Munich Personal RePEc Archive, Paper No. 22912.

Barney, G., Kreutzer, W. B., \& Garrentt, M. J. (1991). Managing a Nation: The Microcomputer Software Catalog. Institute for 21st Century Studies and Westview Press.

Barro, R. J., \& Lee, J. W. (2013). A New Data Set of Educational Attainment in the World, 1950-2010. Journal of Development Economics, 104, 184-198. https://doi.org/10.1016/j.jdeveco.2012.10.001

Behrman, J. R. (1996). The Impact of Health and Nutrition on Education. The World Bank Research Observer, 11, 23-37. https://doi.org/10.1093/wbro/11.1.23

Calderón, C., \& Servén, L. (2004). The Effects of Infrastructure Development on Growth and Income Distribution. WPS3400, Washington DC: World Bank.

https://doi.org/10.1596/1813-9450-3400 
Cho, J., Isgut, A., \& Tateno, Y. (2017). Pathways for Adapting the Sustainable Development Goals to the National Context: The Case of Pakistan. Asia Pacific Development Journal, 24, 53-87.

Davood, S. (2009). Monitoring the Quality of Secondary Education in the Context of Decentralization in Pakistan. Bulletin of Education and Research, 31, 1-25.

Diemer, A. (2004). World Model, System Thinking and System Dynamics (20 p). Working Paper, HERMES, Université Reims Champagne Ardennes.

Diemer, A. (2020). Modéliser le COVID. Revue Francophone du Développement Durable, No. 15, 1-72.

Diemer, A., Khushik, F., \& Ndiaye, A. (2020). SDG 4, Quality Education, the Cornerstone of the SDGs: Case Studies of Pakistan and Senegal. Journal of Economics and Development Studies, 8, 9-32.

Durrani, N., \& Halai, A. (2018). Dynamics of Gender Justice, Conflict and Social Cohesion: Analysing Educational Reforms in Pakistan. International Journal of Educational Development, 61, 27-39. https://doi.org/10.1016/j.ijedudev.2017.11.010

Forrester, J. (1961). Industrial Dynamics. Cambridge: The MIT Press.

Forrester, J.J. (1969). Urban Dynamics. Cambridge: The MIT Press.

Ghaus, K., Ahmed, N., Khan Toru, S., Manzoor, R., \& Sohaib, M. (2015). Implications of Implementing SDGs at the National Level: A Case of Pakistan (18 p). Southern Voice Occasional Paper 32.

Goodman, M. (1997). Systems Thinking: What, Why, When, Where and How? Systems Thinkers, 8, 6-7.

Hameed-ur-Rehman, M., \& Sadruddin Sewani, S. M. (2014). Critical Analysis of the Educational Policies in Pakistan. The Dialogue, 8, 247-260.

Hunter, R. (2020). Education in Pakistan. World Education Services. https://wenr.wes.org/2020/02/education-in-pakistan

Iqbal, Z., \& Zahid, G. M. (1998). Macroeconomic Determinants of Economic Growth in Pakistan. The Pakistan Development Review, 37, 125-148. https://doi.org/10.30541/v37i2pp.125-148

Jalil, A., \& Idrees, M. (2013). Modeling the Impact of Education on the Economic Growth: Evidence from Aggregated and Disaggregated Time Series Data of Pakistan. Economic Modelling, 31, 383-388. https://doi.org/10.1016/j.econmod.2012.11.035

Kakakhel, S. (2015). Is Pakistan Ready for the Paris Summit? The Thirdpole.net. https://www.thethirdpole.net/2015/11/27/is-pakistan-ready-for-paris-summit

Khan, A. J., \& Ali, W. (2019). Capacity Development Challenges in the way of SDGs Implementation in Pakistan (14 p). Working Paper No. 166, Sustainable Development Policy Institute (SDPI).

Khemka, N. M., \& Kumar, S. (2020). Social Development and the Sustainable Development Goals in South Asia. London: Routledge. https://doi.org/10.4324/9781351035262

Khushik, F., \& Diemer, A. (2018). Critical Analysis of Education Policies in Pakistan: A Sustainable Development Perspective. Social Science Learning Education Journal, 3, 1-16. https://doi.org/10.15520/sslej.v3i09.2282

Khushik, F., \& Diemer, A. (2020a). Sustainable Development Goals and Education in Pakistan, the new challenges for 2030. In A. Diemer et al. (Eds.), Paradigms, Models, Scenarios and Practices for Strong Sustainability (pp. 359-370). Clermont-Ferrand: Oeconomia.

Khushik, F., \& Diemer, A. (2020b). Education and Sustainability, How SDG4 Contributes to Change the Representations of Developing Issues? The Case Study of Pakistan. In- 
ternational Journal of Management and Sustainability, 9, 101-119.

https://doi.org/10.18488/journal.11.2020.92.101.119

Leipziger, D., Fay, M., Wodon, Q., \& Yepes, T. (2003). Achieving the Millennium Development Goals: The Role of Infrastructure. The World Bank Policy Research Working Paper 3163. https://doi.org/10.1596/1813-9450-3163

McGrath, S., \& Powell, L. (2016). Skills for Sustainable Development: Transforming Vocational Education and Training Beyond. International Journal of Educational Development, 50, 12-19. https://doi.org/10.1016/j.ijedudev.2016.05.006

Meadows, D. (1999). Leverage Points: Places to Intervene in a System. Hartland: The Sustainability Institute.

Millennium Institute (2007a). Technical Documentation for the Threshold 21 Starting Framework Model. Millennium Institute.

Millennium Institute (2007b). A Technical Introduction to Threshold 21 Integrated Development Model. Millennium Institute.

Millennium Institute (2017). Threshold 21 (T21), ISDG Model. Model Documentation, Version of january 15th. Washington DC: Millennium institute.

Mochizuki, Y. (2019). Rethinking Schooling for the 21st Century: UNESCO-MGIEP's Contribution to SDG 4.7. Sustainability, The Journal of Record, 12, 88-92. https://doi.org/10.1089/sus.2019.29160

Parveen, A., Rashid, K., Iqbal, M. S., \& Khan, S. (2011). System and Reforms of Higher Education in Pakistan. International Journal of Business and Social Science, 2, 260-267.

Pritchett, L., \& Filmer, D. (1998). The Effect of Household Wealth on Educational Attainment: Demographic and Health Survey Evidence. Policy Research Working Paper, Washington DC: The World Bank Development Research Group, Poverty and Human Resources.

Pruyt, E. (2013). System Dynamics Models for Big Issues. The Netherlands: TU Delft Library.

Qu, W., Barney, G. O, Symalla, D., \& Martin, L. (1999). The Threshold 21: National Sustainable Development Model in Integrated Global Models of Sustainable Development-Vol. II. Encyclopedia of Life Support Systems (EOLSS).

Rajkumar, A. S., \& Vinaya Swaroop, A. (2002). Public Spending and Outcomes: Does Governance Matter? World Bank Policy Research Working Paper No. 2840.

Rasool Memon, G. (2007). Education in Pakistan: The Key Issue, Problems and the New Challenge. Journal of Management and Social Sciences, 3, 47-55.

Richmond, B. (1997). The "Thinking" in Systems Thinking: How Can We Make It Easier to Master? The Systems Thinker, 8, 1-5.

Richmond, B. (2000). The Thinking in Systems Thinking: Honing Your Skills. The Systems Thinker, 11, 6.

Rizvi, A., Bhatti, Z., Das, J. K., \& Bhutta, Z. A. (2015). Pakistan and the Millennium Development Goals for Maternal and Child Health: Progress and the Way forward. Pediatrics and International Child Health, 35, 287-297. https://doi.org/10.1080/20469047.2015.1109257

Roohi, S. (2007). 35 Research on Global Change in Pakistan. In P. Tarolli, \& S. M. Mudd (Eds.), Developments in Earth Surface Processes (Vol. 10, pp. 329-340). Amsterdam: Elsevier B.V. https://doi.org/10.1016/S0928-2025(06)10035-8

Sayed, Y., \& Ahmed, R. (2015). Education Quality, and Teaching and Learning in the Post 2015 Education Agenda. International Journal of Educational Development, 40, 
330-338. https://doi.org/10.1016/j.ijedudev.2014.11.005

Seeme, M. (2017). For Scientific Perspective on Sustainable Development Goals for Pakistan. Science Vision, 21, 51-62.

Senge, P. M. (1990). The Fifth Discipline. New York: Dell Publishing Group.

Shahidul, S. M., \& Zehadul Karim, A. H. M. (2015). Factors Contributing to School Dropout among the Girls: A Review of Literature. European Journal of Research and Reflection in Educational Sciences, 3, 26-36.

Siddiqui, R. (2006). Modelling Gender Dimensions of the Impact of Economic Reforms in Pakistan. Ninth Annual Conference of GTAP, Addis Ababa, Ethiopia, 15-17 June 2006, 52 p.

Sohoo, M. N., Chandani, A. M., Abro, L. T., \& Khoso, Z. A. (2019). Public-Private Partnership: Understanding the Impact of Educational Management Organizational Model Towards the Fulfillment of Sustainable Development Goal 4 in the context of Sindh Province of Pakistan. Archives of Business Research, 7, 98-112.

Sterman (2000). Business Dynamics, Systems Thinking and Modeling for a complex World. Mc Graw-Hill Higher Education.

Tamim, T. (2014). The Politics of Languages in Education: Issues of Access, Social Participation and Inequality in the Multilingual Context of Pakistan. British Educational Research Journal, 40, 280-299. https://doi.org/10.1002/berj.3041

Umar, M., \& Asghar, Z. (2018). SDG Index for Pakistan at Provincial Level. Munich Personal RePEc Archive (MPRA), Paper No. 83997.

https://mpra.ub.uni-muenchen.de/83997/1/MPRA_paper_83997.pdf

UNESCO (1984). The Dropout Problem in Primary Education. Bangkok, Thailand: UNESCO Regional Office for Education in Asia and the Pacific.

UNESCO (2020). Global Education Monitoring Report: Inclusion and Education, All Means. Paris: UNESCO.

United Nations (2015). Sustainable Development Goals. https://sdgs.un.org/fr

Unterhalter, E. (2019). The Many Meanings of Quality Education: Politics of Targets and Indicators in SDG 4. Global Policy, 10, 39-51. https://doi.org/10.1111/1758-5899.12591

World Bank (2012). Governance and Management in the Education Sector (Cameroon). Report No. 67201-CM, World Bank.

\section{Appendix}

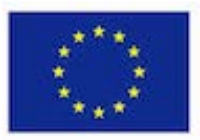

Co-funded by the

Erasmus+ Programme

of the European Union

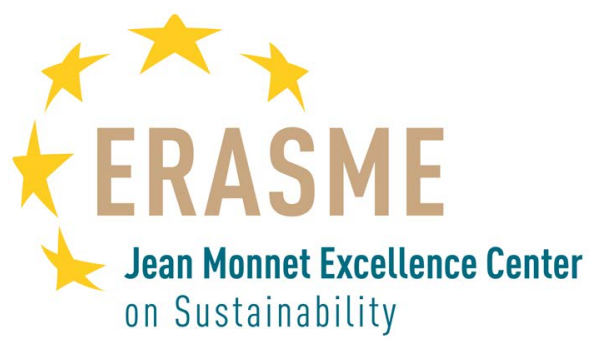

